\title{
Cultivation of granular sludge with hypersaline oily wastewater
}

\author{
Santo Fabio Corsino a, *, Riccardo Campo ${ }^{\text {b }}$, Gaetano Di Bella ${ }^{\text {b }}$, Michele Torregrossa ${ }^{\text {, }}$, \\ Gaspare Viviani ${ }^{a}$ \\ a Dipartimento di Ingegneria Civile, Ambientale, Aerospaziale, dei Materiali, Università di Palermo, Viale delle Scienze, 90128 Palermo, Italy

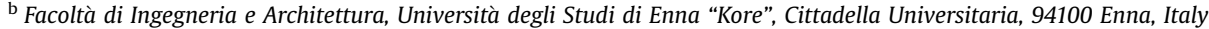

\section{A R T I C L E I N F O}

\section{Article history:}

Received 23 July 2015

Received in revised form

15 September 2015

Accepted 15 September 2015

Available online $\mathrm{xxx}$

\section{Keywords:}

Aerobic granular sludge

Hydrocarbons

Salinity

Granulation

Nutrient removal

\begin{abstract}
A B S T R A C T
The time required to stabilise mature aerobic granules is rather variable. In addition, cultivation time and the structural characteristics of granules seem to be related to the nature of wastewater influent. Granular sludge has been used for the treatment of several industrial wastewaters, but nothing has been reported about wastewater characterized by the simultaneous presence of hydrocarbons and high chloride concentration. In this work, the authors analysed the granulation process and performance as well as the physical characteristics of aerobic granules in two Granular Sequencing Batch Airlift Reactors (GSBARs), fed with acetate-based synthetic wastewater in reactor 1 (R1) and with a mixture of real and simulated slop (R2). The results obtained in 100 days show that full granulation was achieved in both reactors. The granules in R2 developed more quickly, but they appeared slightly unstable and more susceptible to breaking. Despite high salt concentration, the efficiency of phosphorous and carbon removal was satisfactory. Low nitrification activity was observed in R1, confirming that a longer time is necessary to obtain the acclimation of autotrophic biomass in aerobic granules. In R2 the combined effect of salinity and hydrocarbons caused the inhibition of the autotrophic biomass, with the consequence that nitrification was absent. Hydrocarbons were initially removed by adsorption afterwards by biological degradation with a removal efficiency of over $90 \%$.
\end{abstract}

() 2015 Elsevier Ltd. All rights reserved.

\section{Introduction}

In the last decade, aerobic granular sludge has attracted increasing interest as one of the most promising technologies for wastewater treatment. Aerobic granular sludge offers many advantages over conventional activated sludge systems, due to its high metabolic activity, excellent settling capacity, the simultaneous nitrification denitrification (SND) capacity (De Kreuk et al., 2005), and the ability to tolerate and degrade toxic organic compounds, such as phenol, antibiotics, etc. (Liu et al., 2009; Amorim et al., 2014). On account of these, aerobic granules are suited for the treatment of industrial wastewater, containing recalcitrant and xenobiotic substances. Many studies have analysed the granulation process using both industrial and simulated wastewater. Inter alia, Di Bella and Torregrossa (2014) used granular sludge for landfill leachate treatment. Val del Río et al. (2012) treated different industrial wastewater produced by dairy products, in the fish canning

\footnotetext{
* Corresponding author

E-mail address: santofabio.corsino@unipa.it (S.F. Corsino).
}

industry, a plant processing marine products and a pig farm. Recently, Moreira et al. (2015) observed that granular sludge is able to remove fluoxetine via adsorption phenomena. However, in these cases, if contaminants are not degraded biologically, desorption phenomena may occur, causing a significant deterioration in effluent quality (Amorim et al., 2014).

The time required to get stable mature granules is rather variable and seems related to the nature of the influent. Taheri et al. (2012) obtained aerobic mature granules after 70 days treating saline wastewater. Zhang et al. (2011) obtained granular sludge after 140 days treating petrochemical wastewater, while Abdullah et al. (2013) after 60 days treating agro-based wastewater. Hence, it is clear that the start-up of an aerobic granular sludge reactor is strongly influenced by the nature of the wastewater, since the presence of certain substances could promote the granulation process. For example, divalent ions, such as metals ( $\mathrm{Fe}, \mathrm{Al}$ ), were reported to play an important role in microbial aggregation ( $\mathrm{Li}$ et al., 2014). Authors agree that metals bind to the negatively charged particles present on the surfaces of bacteria, and to extracellular polymeric molecules, acting as a bridge promoting bacterial aggregation. At the same time the presence of some 


\begin{tabular}{|c|c|c|c|}
\hline \multicolumn{2}{|c|}{ List of abbreviations } & $\mathrm{PN}_{\mathrm{f}}$ & protein content at the end of the famine phase (f) \\
\hline $\mathrm{AOB}$ & ammonium oxidizing bacteria & PS & polysaccharides \\
\hline BOD & biological oxygen demand & $\mathrm{PS}_{\mathrm{f}}$ & polysaccharides content at the end of the famine phase \\
\hline COD & chemical oxygen demand & & $(f)$ \\
\hline DO & dissolved oxygen & $\mathrm{PS}_{\mathrm{F}}$ & polysaccharides content at the end of the feast phase \\
\hline EPSs & extracellular polymeric substances & & $(\mathrm{F})$ \\
\hline $\mathrm{F} / \mathrm{M}$ & food to microorganisms ratio & SND & simultaneous nitrification denitrification \\
\hline GAOs & glycogen accumulating organisms & SRT & sludge retention time \\
\hline GSBARs & granular sequencing batch airlift reactors & $\mathrm{TN}$ & total nitrogen \\
\hline HRT & hydraulic retention time & $\mathrm{TP}$ & total phosphorus \\
\hline MLSS & mixed liquid suspended solids concentration & TPHs & total petroleum hydrocarbons \\
\hline MLVSS & mixed liquid volatile suspended solids & TSS & total suspended solids \\
\hline NOB & nitrite oxidizing bacteria & VER & volumetric exchange ratio \\
\hline PAOs & polyphosphate accumulating organisms & VSS & volatile suspended solids \\
\hline PN & proteins & & \\
\hline
\end{tabular}

compounds such as metal ( $\mathrm{Cd}, \mathrm{Pb}, \mathrm{Cu}, \mathrm{Zn}, \mathrm{Mn})$, chloride, hydrocarbons, surfactants and others, may inhibit some bacterial strains and consequently the system performance is lowered (Pronk et al., 2014). Therefore, if on one hand these compounds can accelerate the granulation, on the other they can have adverse effects on biological performance. For these reasons, the treatment of industrial wastewater is a complex research topic.

In recent years, great attentions has been paid to oily wastewater generated by ships in the engine-rooms (bilge water) and by the washing of oil tanks (slops) (Sun et al., 2010; Di Bella et al., 2014). This "special" wastewater is a complex mixture of various compounds such as solvents, surfactants, metal salts, oils and so on. The presence of such substances, in conjunction with the high salinity levels (up to 25.000 p.p.m.), make conventional biological systems unsuitable for their treatment. In literature there are several studies about the treatment of saline wastewater using granular sludge (Bassin et al., 2011; Pronk et al., 2014), while few are relating to the treatment of wastewater contaminated with hydrocarbons (Zhang et al., 2011). However, no experiences on granulation process both with saline and oily wastewater have been reported. Therefore, the combined effect of salinity and hydrocarbons on aerobic granular sludge formation and structural characteristics, as well as its biological performance, needs to be investigated.

The aim of this work was to analyse the granulation process and the physical characteristics of granules in two Granular Sequencing Batch Airlift Reactors (GSBARs). One of the GSBAR was fed with acetate-based synthetic wastewater (R1), while the other (R2) was fed with a mixture of real slop and simulated slop. Granulation rate in time and granule characteristics were investigated, in terms of sizes, density, settling velocity, water content, EPS production, nutrients and hydrocarbon removal.

\section{Materials and methods}

\subsection{Pilot plant description}

Experiments were carried out for 100 days in two GSBARs as described by Beun et al. (2002). The first GSBAR, called R1, was inoculated with activated sludge collected from Palermo's municipal wastewater treatment plant, while the second, called R2, was inoculated with activated sludge, collected from a BiofilmMembrane BioReactor (BF-MBR) bench scale reactor treating slop.

$\mathrm{R} 1$ was fed with acetate-based synthetic wastewater, while R2 was fed with a mixture of slop (20 percent in volume) and simulated slop (80 percent in volume). In the simulated slop, a known amount of sodium acetate was added, in order to obtain the same COD of real slop $\left(\approx 1300 \mathrm{mg} \mathrm{l}^{-1}\right)$.

The synthetic wastewater had the same composition described by Beun et al. (2002). The characteristics of R1 and R2 influents are summarized in Table 1.

In order to compare the granulation processes and the features of the granules, the main operating conditions were kept the same for both reactors. Each reactor had a working volume of $3.5 \mathrm{~L}$ with an internal diameter of $8.6 \mathrm{~cm}$ and a filling height of $60 \mathrm{~cm}$. Both reactors contained an internal riser $(50 \mathrm{~cm}$ high and $5.4 \mathrm{~cm}$ internal diameter). Air was introduced via a fine bubble aerator at the base of the reactor. The effluent was discharged using a solenoid valve placed at $30 \mathrm{~cm}$ from the base of the reactor, and the volumetric exchange ratio (VER) was $50 \%$ in each cycle.

The reactors operated with different cycle length. $\mathrm{R} 1$ operated in $3 \mathrm{~h}$ cycles, consisting of $10 \mathrm{~min}$ of influent feeding, $160 \mathrm{~min}$ of aeration, 5 min of settling and 5 min of effluent withdrawal. In R2 on the other hand, to promote hydrocarbon biodegradation, in line with other studies reported in the literature concerning oily wastewater treatment (Pendashteh et al., 2012), a longer cycle length was imposed, so that the cycle length would not limit the biodegradation process. R2 operated in a $12 \mathrm{~h}$ cycle, consisting of $10 \mathrm{~min}$ of influent feeding, $700 \mathrm{~min}$ of aeration, $5 \mathrm{~min}$ of settling and 5 min of effluent withdrawal. Hydraulic selection pressure was the same for both reactors, and only particles with a settling velocity higher than $3.6 \mathrm{~m} \mathrm{~h}^{-1}$ were kept within the reactors. Because

Table 1

Influent characteristics of Reactor 1 and 2 (measurement unit is $\mathrm{mg} \mathrm{L}^{-1}$ for each parameter).

\begin{tabular}{lll}
\hline Parameter & Reactor 1 & Reactor 2 \\
\hline COD & $900 \pm 15$ & $1350 \pm 50$ \\
$\mathrm{BOD}_{5}$ & $850 \pm 20$ & $1150 \pm 50$ \\
$\mathrm{TOC}$ & $380 \pm 10$ & $550 \pm 25$ \\
$\mathrm{~N}-\mathrm{NH}_{4}$ & $90 \pm 5$ & $105 \pm 5$ \\
$\mathrm{TN}$ & $90 \pm 5$ & $115 \pm 10$ \\
$\mathrm{TP}$ & $20 \pm 2$ & $25 \pm 3$ \\
Total petroleum hydrocarbons (TPHs) & - & $6.8 \pm 1.5$ \\
Aromatic hydrocarbons & - & $1.18 \pm 0.25$ \\
Chloride & 225 & 25,000 \\
Pb & - & $<2$ \\
Cu & - & $<2$ \\
Mn & - & $<2$ \\
Zn & - & $<2$ \\
Surfactant (SDBS) & - & $30 \pm 3$ \\
\hline
\end{tabular}


of different influent organic loads, the F:M ratio was balanced in R1 and R2 controlling the suspended solid (SS) concentration within reactors. In order to maintain the same hydraulic share forces in both reactors, air flow velocity was controlled by a flow-meter in a range of $3.5 \pm 0.5 \mathrm{~cm} \mathrm{~s}^{-1}$. C: $\mathrm{N}$ ratio in $\mathrm{R} 1$ was $10: 1$. The same ratio was kept in $\mathrm{R} 2$ by adding ammonium chloride $\left(\mathrm{NH}_{4} \mathrm{Cl}\right)$ according to BOD variation. Operating conditions are summarized in Table 2.

Dissolved oxygen (DO) concentration was not limited, consequently its concentration ranged from 4 to $8 \mathrm{mg} \mathrm{l}^{-1}$ during the aeration phase. Cycling SBR operations have been automatically handled by a Programmable Logic Controller (PLC).

\subsection{Analytical procedures}

All the physico-chemical analysis (TOC, COD, BOD, $\mathrm{NH}_{4}-\mathrm{N}$, $\left.\mathrm{NO}_{3}-\mathrm{N}, \mathrm{NO}_{2}-\mathrm{N}, \mathrm{PO}_{4}-\mathrm{P}, \mathrm{TSS}, \mathrm{VSS}\right)$ were performed according to standard methods (APHA, 2005) twice a week. In addition, sizes of granules, density, settling velocity, sludge volume index after 5 min of settling $\left(\mathrm{SVI}_{5}\right)$, hydrophobicity, and EPSs were performed once a week to limit the sludge withdrawal. In R2 the Total Petroleum Hydrocarbons (TPHs) measurements were carried out after the 55th day at regular time intervals, when pseudo-steady-state conditions, in terms of granule sizes and SS concentrations were reached. The size of granules, in the first phase, was measured by laser diffraction (Malver Mastersizer ${ }^{\circledR}, 2000$ series) with tap water as the suspension medium and standard optical parameter. Hereafter, when granule sizes exceeded $2 \mathrm{~mm}$, dimensions were analysed by digital image capture by means of a stereo-microscope. Afterwards, granule size distribution was obtained by measuring a significant number of particles (approximately 500) using an image analyzer (Di Bella and Torregrossa, 2013). Granulation rate was evaluated as the percentage of particles with a diameter over $600 \mu \mathrm{m}$, according to Liu et al. (2012). The density of granular sludge was determined using the Dextran Blue method described by Beun et al. (2002).

The settling velocity was determined by placing individual granules in a graduated cylinder and measuring the time it took to drop from a fixed height (Bartrolí et al., 2010). The hydrophobicity of the cell surface was determined with the method described by Rosenberg et al. (1980). EPSs analysis were carried out by the Heating Method described by Le-Clech et al. (2006), which consists of a two-step process to extract first Soluble Microbial Products (SMPs), then EPS bound (EPSb) afterwards. The carbohydrates were determined according to the phenol-sulphuric acid method with glucose as the standard (Dubois et al., 1956), while the proteins were determined by the Folin method with bovine serum albumin as the standard (Lowry et al., 1951). In this work the total EPSs content $\left(\mathrm{EPS}_{\mathrm{T}}\right)$ was considered as the sum of the protein and carbohydrate content, which are the dominant polymeric constituents. The samples for EPSs analysis were taken twice in a reaction cycle. The first was taken when most of the substrate was oxidized (end of the feast phase), while the second was taken at the end (end of the famine phase). DO concentration was monitored during the cycle in order to identify the end of the feast phase as described by Di Bella and Torregrossa (2013). The TPHs concentration was measured by means of soxhlet extraction from samples with hexane and gas chromatography equipped with a flame ionization detector (GC-FID, Agilent 6890N), in accordance to standard methods (APHA, 2005). The analysis of EPSs, density, hydrophobicity, TSS and VSS were done in triplicates, while THPs were run five times. All the other measurements were done one time. In order to evaluate the contribution of each parameter on physical characteristics of granular sludge, the simple multiple linear regression method was applied. According to this method, the Pearson linear correlation has been used in order to investigate the statistical significance of the linear correlations.

\section{Results and discussion}

\subsection{Granules formation}

Stable aerobic granules in both reactors was obtained, although the cultivation time was different. In R1 after 14 days a small number of fine bio-aggregates with a diameter over $0.6 \mathrm{~mm}$ started to appear, showing the beginning of the granulation process. A significant number of granules were visible only after 44 days. These granules had a regular outer shape and exhibited a yellow appearance (Fig. 1a), in accordance with aerobic granules cultivated with synthetic wastewater in other studies (Tay et al., 2001). On the 98th day, a discrete number of mature granules with an average diameter of $1 \mathrm{~mm}$ were visible within a heterogeneous mixture of small granules and flocculent sludge (Fig. 1b).

In R2 the granules developed more quickly. After 15 days large granules with a diameter over $1 \mathrm{~mm}$ were observed (Fig. 1c). Gradually, granules with a diameter of $2 \pm 0.5 \mathrm{~mm}$ prevailed in the reactor after 30 days (Fig. 1d). These granules had a smooth outer surface and were characterized by a brownish colour. At the end of the observation period (98th day), the mature granules had an average size of $1.9 \mathrm{~mm}$.

In Fig. 1e, f, the granules sizes and the granulation rate are shown. In R1, both granule sizes and granulation rate increased for the whole cultivation period. The size of the mature granules (98th day) were almost $1 \mathrm{~mm}$ and the granulation rate was almost $30 \%$.

In $\mathrm{R} 2$, both the granule sizes and the granulation rate resulted higher for the whole cultivation period. The mature granules were dominant after 30 days, with a granulation rate of about $60 \%$. The granulation rate then slowly decreased to a steady-state value (about 40\%) at the end of the observation period (the 98th day), despite the granules average diameter remaining about $2 \mathrm{~mm}$. It is possible that, as theorized by Verawaty et al. (2013), the R2 granules had reached their critical size. In more detail, the granules larger than the critical size would be more prone to undergo breakage or attrition, due to the consequences of particle collision energies and structural weaknesses. The granule sizes remained quite stable on average, because the growth and the detachment of outer layers were balanced. The sludge resulting from the granule detachment mainly settled in less than $5 \mathrm{~min}$, therefore it was not washed out with the effluent and consequently the granulation rate decreased.

\subsection{Physical characteristics of aerobic granules}

In order to compare the granules physical characteristics, EPS content, cell hydrophobicity, MLVSS/MLTSS ratio, density, settling capacity and effluent suspended solids concentration were

Table 2

Operating conditions for Reactor 1 and 2.

\begin{tabular}{|c|c|c|c|c|c|c|}
\hline & Cycle length [min] & Settling time [min] & VER [\%] & $\mathrm{F}: \mathrm{M}\left[\mathrm{KgBOD}_{\mathrm{KgVSS}}{ }^{-1} \mathrm{~d}^{-1}\right]$ & Air flow velocity [ $\left.\mathrm{cm} \mathrm{sec}^{-1}\right]$ & $\mathrm{C}: \mathrm{N}[-]$ \\
\hline Reactor 1 & 180 & 5 & 50 & $0.42 \pm 0.10$ & 3.5 & $10: 1$ \\
\hline Reactor 2 & 720 & 5 & 50 & $0.41 \pm 0.25$ & 3.5 & $10: 1$ \\
\hline
\end{tabular}


Reactor 1
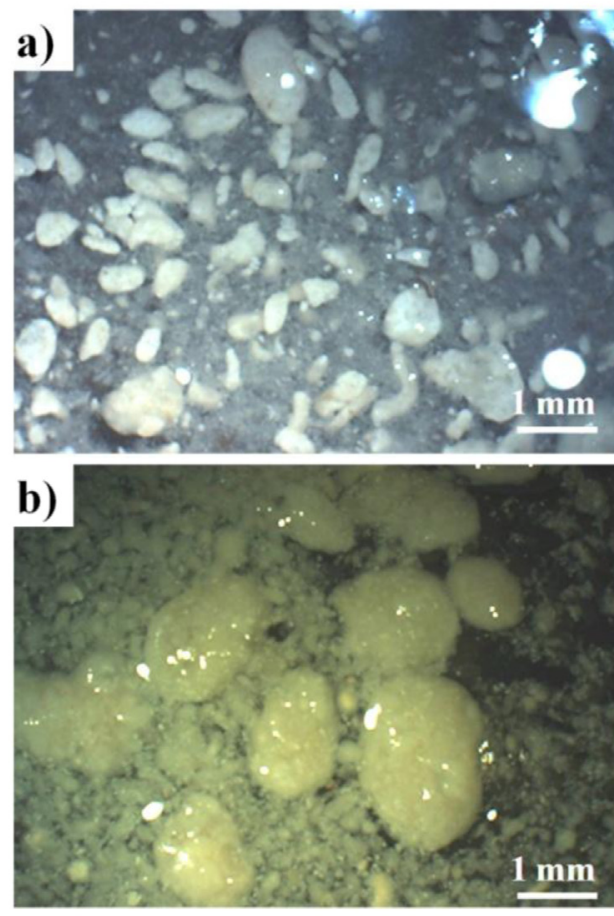

e)

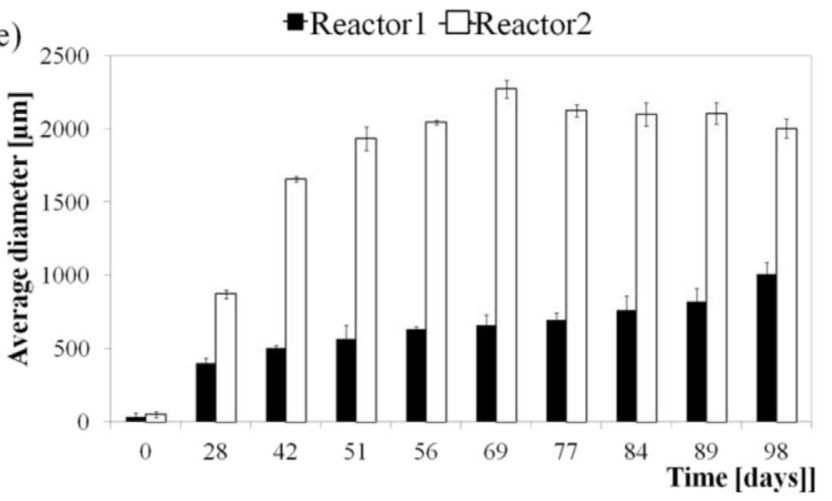

Reactor 2
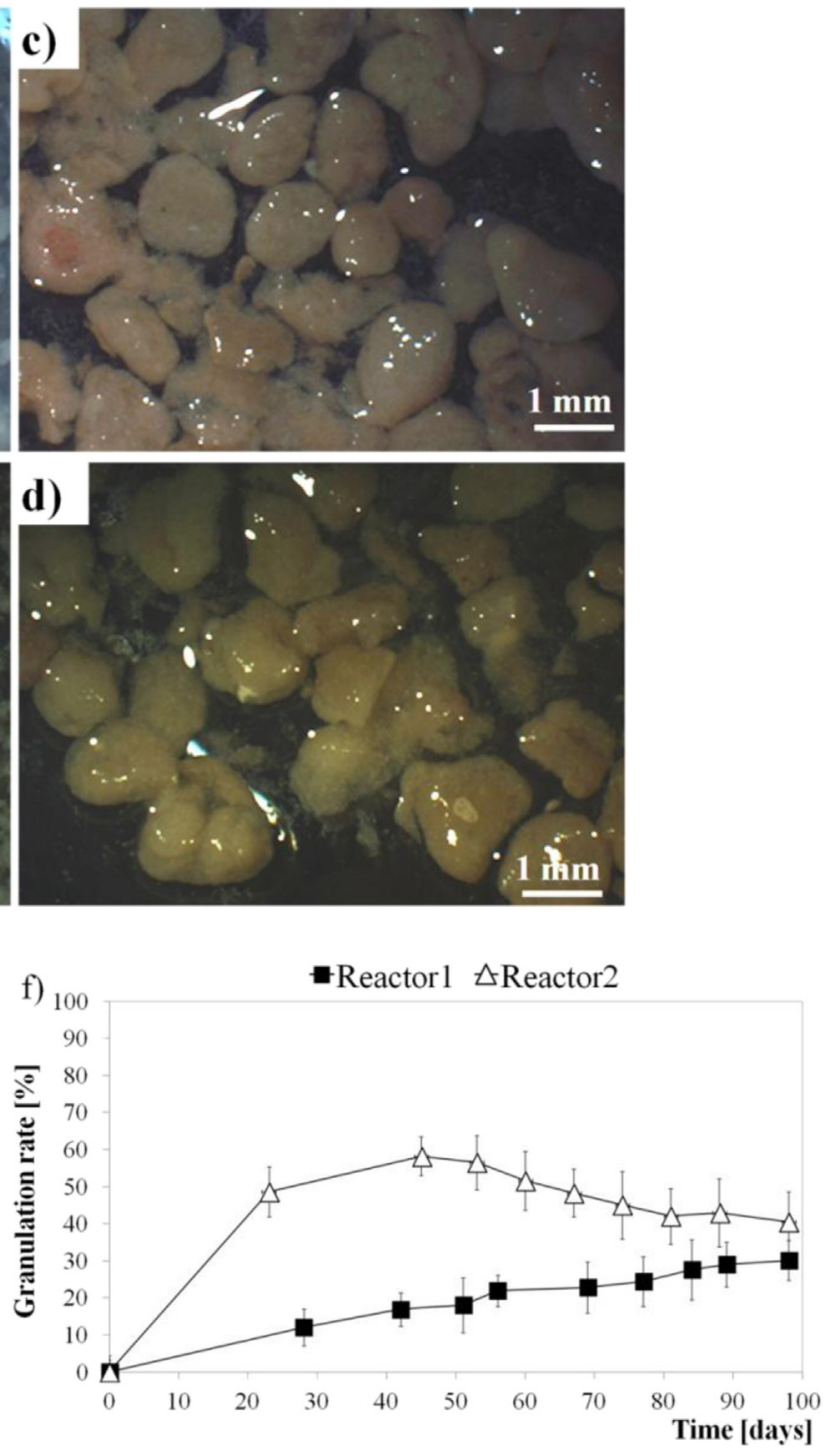

Fig. 1. Reactor 1 granules at 44 day (a) and 98 (b); Reactor 2 granules at 15 day (c) and 30 (d); granules sizes (e) and granulation rate (f) during cultivation period.

analysed.

EPSs play a major role in granular sludge formation and stability. In a typical sequencing batch reactor (SBR) reaction cycle, two different phases can be identified. In the former, that is characterized by high substrate availability (feast phase), microorganisms degraded the substrate producing EPSs, which served as a carbon and energy source for the endogenous respiration in the latter period (famine phase). As a consequence, the EPSs content was modified during the reaction cycle. Few authors reported EPSs variation during a reaction cycle (Zhu et al., 2012), but no information are available about their changes during the whole granulation process.

In order to clarify this, the protein and polysaccharide content of granular sludge was analysed at the end of both the feast and famine periods. The protein fraction (PN) of EPS was much higher than the polysaccharide fraction (PS) in both granular sludges. EPS content showed a "saddle" trend in both reactors, but slightly shifted in time (Fig. 2a, b). In the earlier stages of the granulation process, a significant PS and PN production was observed. Protein and carbohydrate content rose quickly, then reduced significantly.
As reported by Zhu et al. (2012) in this phase, the microorganisms began to adjust their metabolisms to the new feed and high shear forces, so the EPS content grew rapidly. In this period the first bioaggregates appeared in the reactor. However granules did not prevail in the bioreactor, but were dispersed in a suspension of flocculent sludge. Due to sludge wash-out, which generally characterizes the early stages of the granulation process, the EPS content decreased. As the poor-settling microorganisms were discharged, and the microbial community with good flocculation were enriched in the reactor, PN and PS content increased again. In this phase other dense and stable granules formed and sludge became granular (maturation phase). It would appear that polysaccharides favour the formation of isolate bio-aggregates, while the proteins determine the granulation of sludge. As reported by Zhang et al. (2011) the increasing of the PN:PS ratio was accompanied by the formation of aerobic granules.

In R1, although the protein content was higher than the polysaccharides content, the latter developed more rapidly in the first 30 days; in fact, as can be observed in Fig. 2c, PN:PS ratio reduced in this period. Due to their simpler molecular structure, 


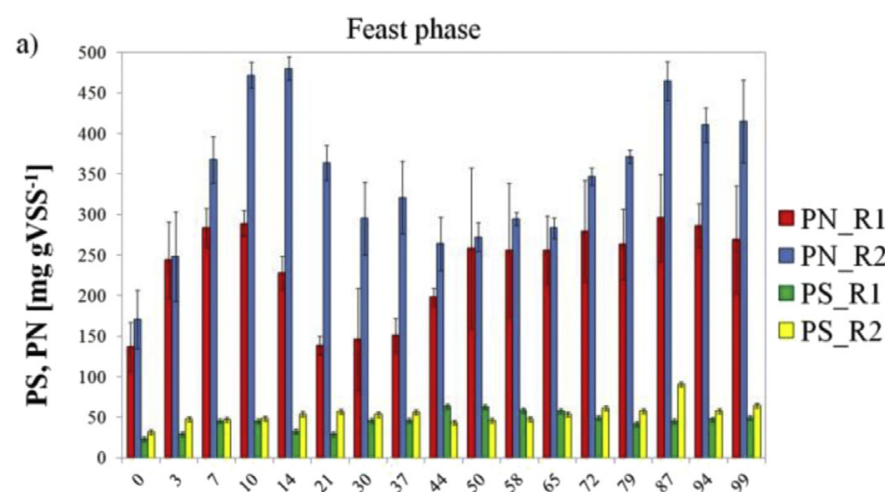

Time [days]

c)

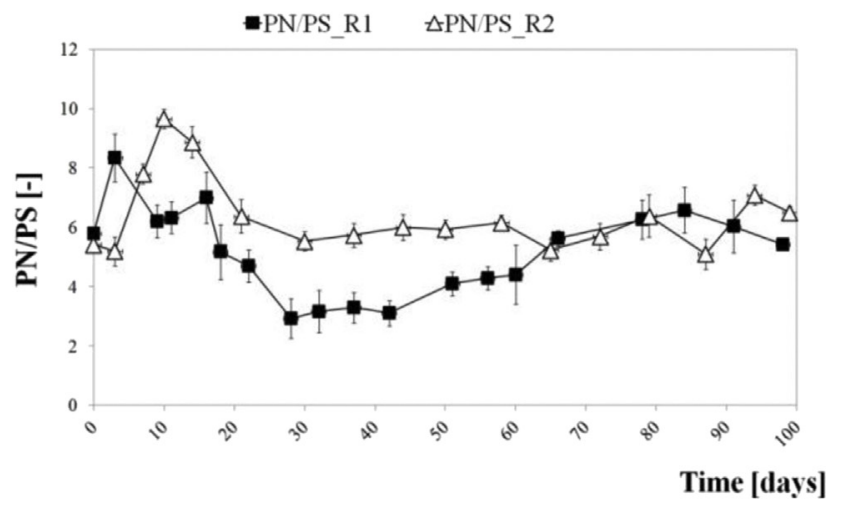

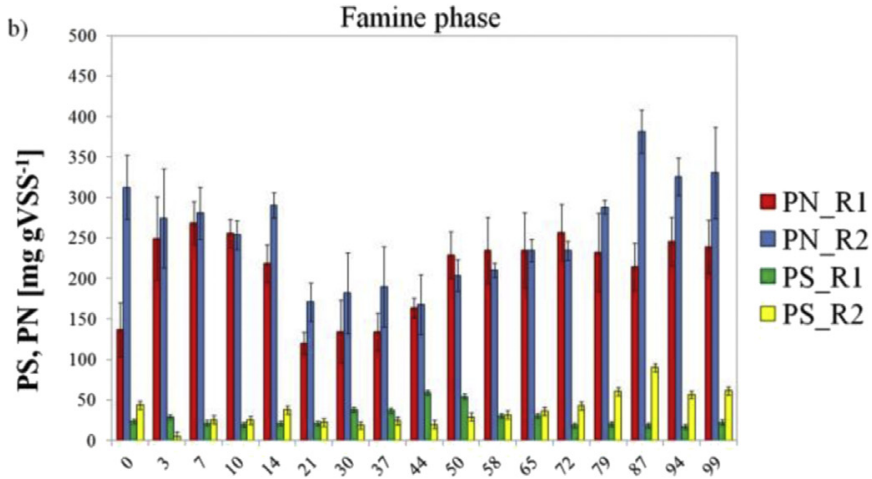

Time [days]

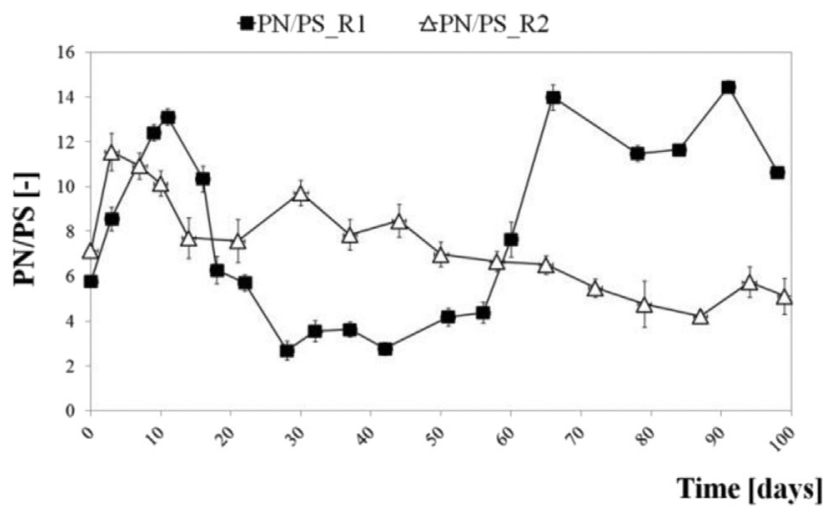

Fig. 2. EPS (a), (b) and PN/PS ratio (c), (d) trend with time in feast/famine periods.

polysaccharides are perhaps synthesized more rapidly than protein molecules that are structurally more complex. Hereafter, PN content increased significantly, so PN:PS ratio grew from 3 to 6 . A steady-state condition was reached after 65 days. Maximum PS and PN production was observed at the end of the feast period, as observed also by Zhu et al. (2012). PS and PN concentrations reached their maximum values, when most of the organic substrate was removed from the bulk (feast phase), after 20 and $45 \mathrm{~min}$ on average, in R1 and R2 respectively. When the maturation of the granules occurred at the end of the feast phase the PN content was about 6-7 times greater than the PS. In the famine period, the PN and PS content decreased for the whole duration of the experiment. In detail, it was noticed that, when large mature granule begin to appear in bioreactor, PN content reduced on average of about $14-15 \%$, while PS content reduced about $40 \%$, hence PN:PS ratio increased during the famine period up to 13 . This was probably due to PS consumption by microorganisms during the starvation phase (Adav and Lee, 2008). The large granule sizes and their density in fact, may constitute a barrier to nutrient diffusion inside the inners layers, so microorganisms in the absence of primary substrate used carbohydrates instead of proteins due to their simpler molecular structure. Zhu et al. (2012) in their study reported that about $50 \%$ of proteins and $47 \%$ of carbohydrates were consumed during the starvation phase. In this case the difference in protein reduction is due to the shorter duration of the starvation phase ( $2.5 \mathrm{~h}$ vs $10 \mathrm{~h}$ ); specifically, it is possible to note that in the first phase of the famine period, the microorganisms preferentially consume storage PS, using the PN only at a later time.

Due to salinity and hydrocarbons in R2 significant differences with R1 were found. The protein content was much higher than the carbohydrate content; however, their ratio increased in comparison with the early days: when steady-state conditions were reached, at the end of the feast phase their ratio stabilized around 6, while in the famine phase it was around 8 (Fig. 2d). The difference with respect to $\mathrm{R} 1$ was due to the longer duration of the famine period, which induced microorganisms to degrade more polymers as carbon and energy sources for endogenous respiration in the aerobic starvation phase. In this case, PN and PS reduction was about 40 and 60 percent on average respectively. Therefore also a substantial rate of protein was consumed, resulting in the decreasing of the PN:PS ratio with respect to $\mathrm{R} 1$. Compared to R1 granules, R2 EPSs content was higher; indeed, during granule formation, EPS content was about $550 \mathrm{mg} \mathrm{gVSS}^{-1}$ vs $340 \mathrm{mg} \mathrm{gVSS}^{-1}$ at the end of the feast phase, while at the end of the famine period, more comparable values were observed $\left(250 \mathrm{mg} \mathrm{gVSS}^{-1}\right)$. During the feast phase, PN content was almost double in the R2 granules, while PS content was similar. During the famine phase, PN, as well as PS content in R2, despite their significant reduction comparing with the feast phase, remained higher than R1. Therefore, it is possible to assert that granules developed earlier in $\mathrm{R} 2$ due to greater PN production during the feast phase. The results obtained are in agreement with Taheri et al. (2012) and Wan et al. (2014), who observed that under high saline conditions microorganisms produce more EPS, to regulate their osmotic pressure with the outside. With PN content increasing, the sludge surface properties underwent a modification; the positive charges of the amino groups reduced the sludge surface electronegativity (Zhu et al., 2012). In addition, proteins bonding with the metal ions and oily particles content in influent wastewater could also reduce cell surface electronegativity, thus contributing to microbial aggregation.

Sludge hydrophobicity showed a similar trend with time respect to EPS content. As can be observed in Fig. 3a, hydrophobicity increased in both reactors in the early days of the granulation process, then decreased significantly for a few days and at the end 
increased slowly to a steady-state value. During the first four weeks, R2 granules exhibited a higher hydrophobicity with respect to R1 (93\% vs $89 \%$ ). Hereafter, hydrophobicity was higher in R1. These results highlighted that EPS strongly affected sludge hydrophobicity. Indeed, proteins are hydrophobic compounds, hence produce sludge hydrophobicity increase, favouring cell adhesion and lastly granule formation. According to these observations, a significant correlation between PN content and cell hydrophobicity has been found. As can be seen in Fig. 3b, in R1 a good correspondence between protein content and cell hydrophobicity was observed. After a first application of the simple multiple linear regression method, it was possible to identify the best relationships, shown in Fig. 3. More in detail, this relationship showed a Pvalue lower than 0.1 , that indicate a good correlation and the statistical independence among the analysed parameters, confirming
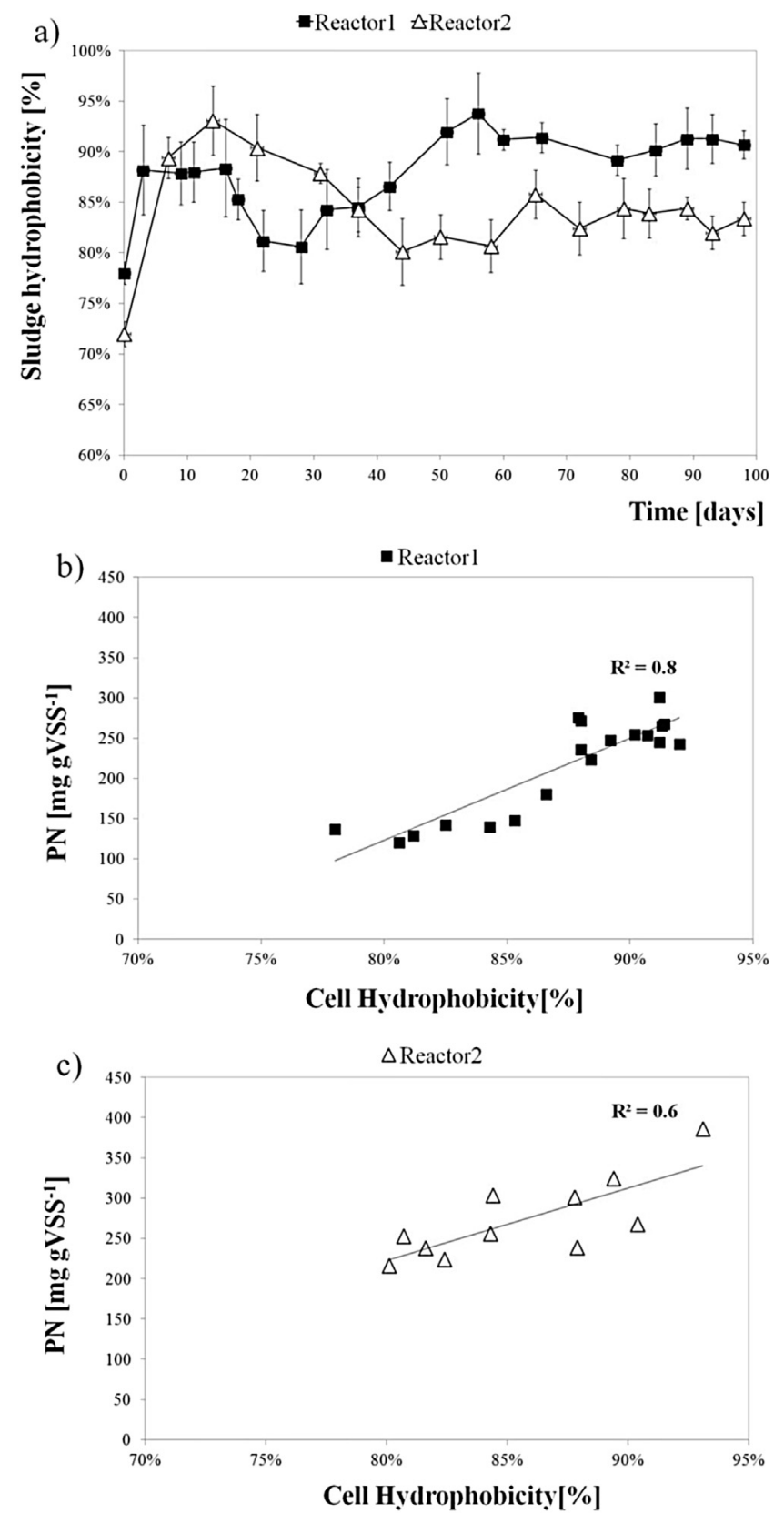

Fig. 3. Hydrophobicity of granular sludge with time (a); correlation between granules hydrophobicity and EPS proteins content in R1 (b) and R2 (c). the key role proteins played in the modification of the physical properties of granules. In R2 on the other hand (Fig. 3c), the correspondence resulted lower, because both salinity and hydrocarbons have direct and indirect effects on cell hydrophobicity. As reported in other studies (Ismail et al., 2010; Sun et al., 2010; Pendashteh et al., 2012), high salt concentration directly affects sludge hydrophobicity, because $\mathrm{Na}^{+}$ions produce a change in the cell surface properties, while at the same time involving major EPSs production (Taheri et al., 2012; Di Bella et al., 2013; Wan et al., 2014). As for hydrocarbons, nothing has been reported about their effect on EPSs production. Nevertheless, as will be discussed in the following pages, hydrocarbons were adsorbed inside the granules early in the granulation process, contributing to form a thin hydrophobic membrane on the granules that led to an increase in sludge hydrophobicity. Therefore, hydrocarbons had a direct impact on sludge hydrophobicity in R2, which implied the lower correspondence between PN and cell hydrophobicity observed. Therefore, it is possible that oil droplet inclusion, as well as high protein production, mainly caused by influent salinity, had produced a significant sludge hydrophobicity increase, allowing sudden granules formation.

In order to obtain the same F:M ratio in both reactors, the concentration of solids was maintained at about $11 \pm 0.5$ gTSS $1^{-1}$ and $6.5 \pm 0.25$ gTSS $1^{-1}$ in R1 and R2 respectively, by purging periodically a certain amount of granules. Consequently, the sludge retention time (SRT) was $16 \pm 0.4$ days for $\mathrm{R} 1$ and $11 \pm 4$ for $\mathrm{R} 2$ on average. The VSS:TSS ratio was also quite different. In R1 it reached a stationary value of $68 \%$, while in $\mathrm{R} 2$ it was $51 \%$. The lowest values observed in R2 were perhaps due to the trapped oil which tends to be incorporated within the granules (Pendashteh et al., 2012). Sludge density was different for both granule types (Fig. 4). R1 mature granules were characterized by a density of $232 \pm 20$ gTSS $1_{\text {granules, }}^{-1}$ while the R2 granules showed a significantly

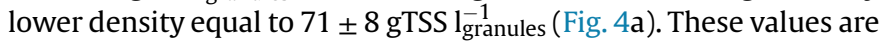
comparable with those observed in other studies with acetatebased synthetic wastewater (Jemaat et al., 2013) and industrial wastewaters (Val del Río et al., 2012). However, it is not clear if the granule density reduction was attributed to high salinity conditions or oil contained in the wastewater and if the effect of the former prevailed on the latter or vice versa. According to Taheri et al. (2012), influent high salt content could cause the formation of granules that exhibit a more porous structure, with granules exhibiting a smaller amount of suspended solid mass per volume. At the same time, it is obvious that the presence of oil droplets within the granules made them less heavy. Probably, both salt and oil act simultaneously on sludge density reduction, but further in depth analysis is needed to clarify their role in density change. It was also noted that there were significant correlations between granule density and VSS:TSS ratio (Fig. 4b, c), although in two different domains of density, as previously observed. Also in this case the P-value resulted lower than 0,1 confirming the statistical independence of these parameters. As reported by Verawaty et al. (2013), the development of bio-aggregate dimensions and their densification, resulted in a gradual reduction of nutrient and oxygen diffusion within the granules. Therefore, the fraction of death cells inside the core and inert material percentage within the granules increased, determining their mass. In addition, in R2 the inclusion of oil droplets within the granules reduced the density and at the same time the VSS:TSS ratio.

According to these results, granule settling velocity resulted higher in R1. Mature R1 granules in fact settled with a velocity of $85 \pm 5 \mathrm{~m} \mathrm{~h}^{-1}$, while in $\mathrm{R} 270 \pm 5 \mathrm{~m} \mathrm{~h}^{-1}$. Despite this slight difference, the $\mathrm{SVI}_{5}$ values were comparable. The $\mathrm{SVI}_{5}$ value in $\mathrm{R} 1$ stabilized around $28 \mathrm{ml} \mathrm{g}^{-1}$ after 78 days, while in $\mathrm{R} 2$ on $30 \mathrm{ml} \mathrm{g}^{-1}$. In spite of substantial density difference, both granular sludges 
a)

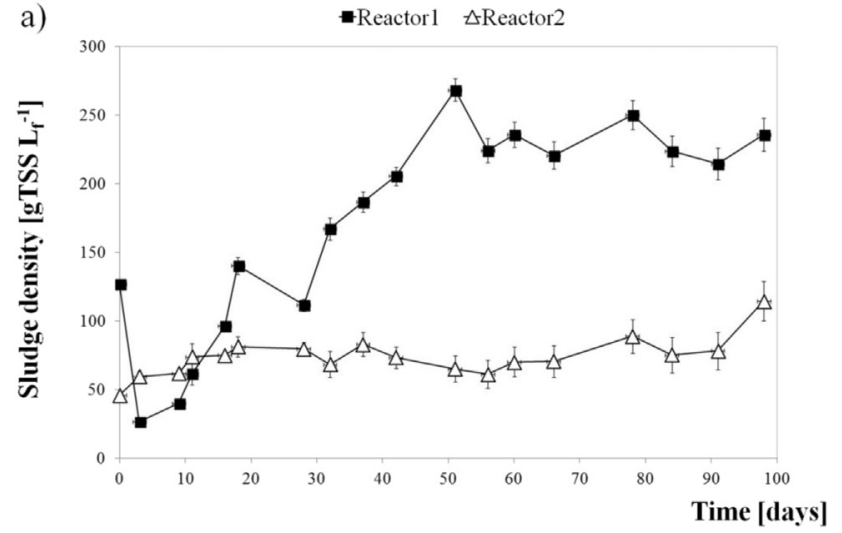

b)

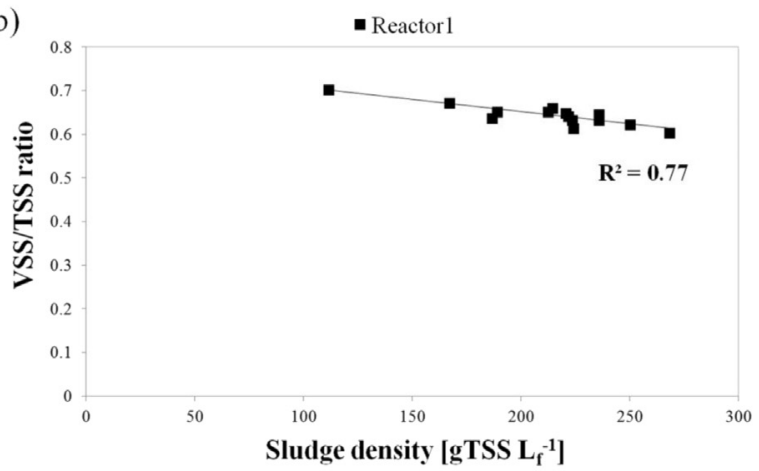

c)

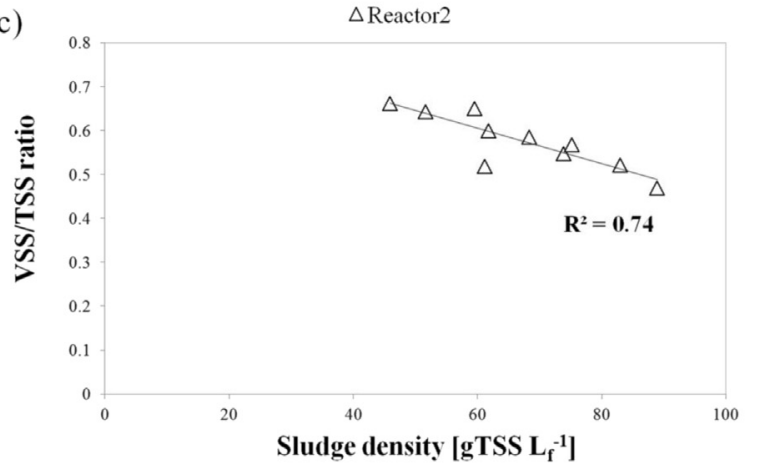

Fig. 4. Granules density trend with time; correlation between granules density and volatile/total suspended solid ratio in R1 (b) and R2 (b).

showed excellent settling capacity. Therefore, as the density favours the development of granules with excellent settling properties, excessively high values of density do not cause a substantial increase in these characteristics. In fact, a very dense structure may be an obstacle to oxygen and nutrient diffusion within the granules as a consequence the nutrient removal process was hindered.

Effluent TSS concentration was higher in R2 (Fig. 5); on the 35th day, a significant increase of suspended solids in R2 effluent was observed, following a partial breaking of granules. TSS concentration in the effluent remained stable for about 40 days, then reduced rapidly while granule strength increased again.

Several reasons for structural granule strength reduction can be put forward. As previously discussed, R2 granules had a higher inert fraction content, as well as a lower density. As observed by Ismail et al. (2010), under strong saline conditions, $\mathrm{Na}^{+}$ions replace $\mathrm{Ca}^{2+}$ ions in the bio-aggregate matrix, so although granules are distinctly bigger, they become weaker and their density reduced. Moreover, the inclusion of oil droplets within the granules resulted in the reduction of the density of the bio-aggregates. In addition, as previously discussed, until the $40^{\text {th }}$ day, a significant EPS content

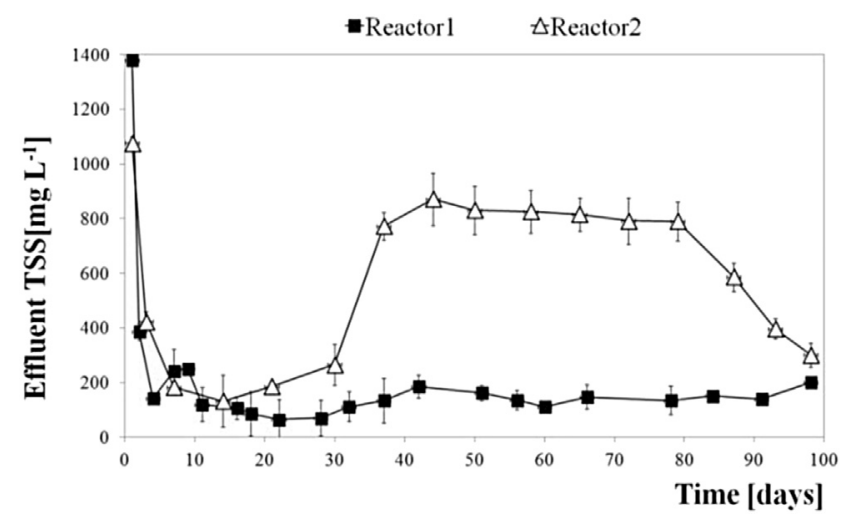

Fig. 5. Total suspended solid concentration in R1 and R2.

reduction during the extended starvation time was observed. In fact, EPS were used by microorganisms as a substrate source during the endogenous starvation time. It is worth to note how PN reduction between the 18 th and $70^{\text {th }}$ day coincided with an effluent suspended solid concentration increase. In addition, after the $70^{\text {th }}$ day, both PN and PS reduction during the famine phase was lower. Therefore, it is possible that PN reduction during the starvation phase is one of the causes of the lower granule density and consequently of their greater structural weakness. Unfortunately, it cannot be exactly established which factors were prevalent. It is probable that all of them have acted synergistically with each other, determining granule weakening. Since both the salt and oil concentration in the influent wastewater were almost stable, it is possible that the role of EPS, and mainly of proteins, was more relevant than others. In fact, the increase of protein (PN) content and the reduction of EPS consumption during the famine period observed after the 58th day, resulted in a higher granule compactness, as proved by less sludge washout.

These results confirm that the granulation process was more rapid when sludge was fed with industrial wastewater (Liu et al., 2011); in fact, under the stress generated by the toxic compounds contained in the industrial wastewater, microorganisms secreted more EPSs (data discussed below), which accelerated the aggregation process. However, the granules were structurally less stable and they were therefore more susceptible to flaking.

\subsection{Organic carbon, nitrogen and phosphorous removal}

In Fig. 6 data related to nutrient removal are shown. In both reactors, removal efficiency of organic matter was satisfactory.

COD removal efficiency was higher in R1 (Fig. 6a), in which reached values of about $98 \%$, while in R2 (Fig. 6b) it was slightly lower (about 88\%). Bearing in mind that the main organic carbon source in R2 was sodium acetate (about 80 percent), it is plausible that this was almost completely oxidised, while the other organic components such as hydrocarbons, or rather recalcitrant compounds contained in the real slop, were not completely metabolized by microorganisms. As a result carbon efficiency removal was low. However, as COD measurements might be affected by high salinity of samples, direct total organic carbon analysis (TOC), was also performed (data not showed). TOC removal efficiencies were about $90 \%$, confirming the results obtained with COD analysis. Accordingly, high salinity conditions and the presence of hydrocarbons had no significant effect on the efficiency of organic matter removal, probably due to previous biomass acclimation.

As for nitrogen, very poor removal was observed in both reactors. The authors point out that nitrogen, as well as the efficient removal of phosphorous were not the main focus of this study. 

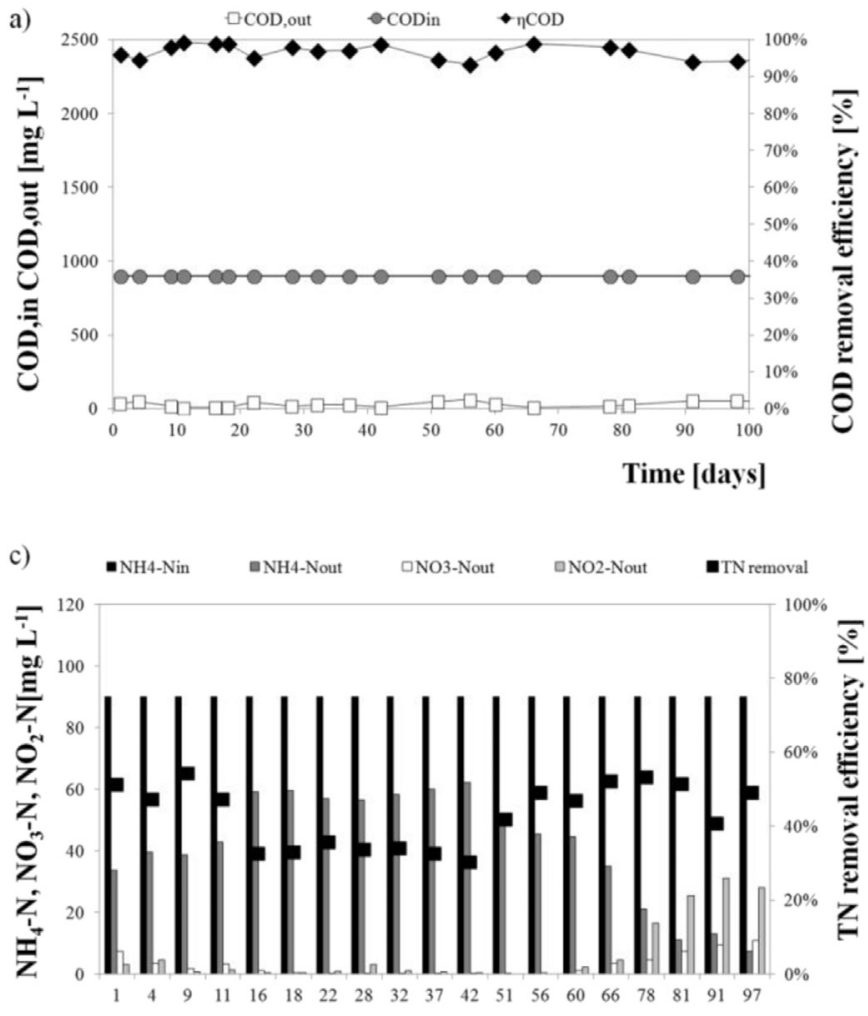

Time [days]

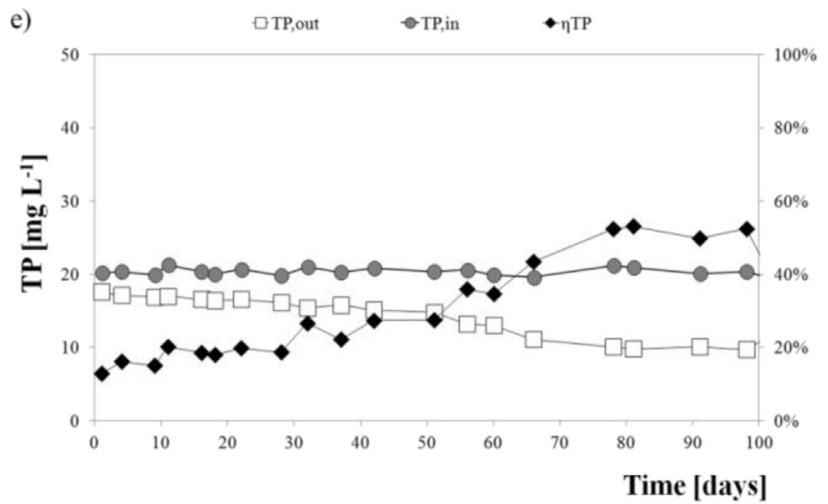

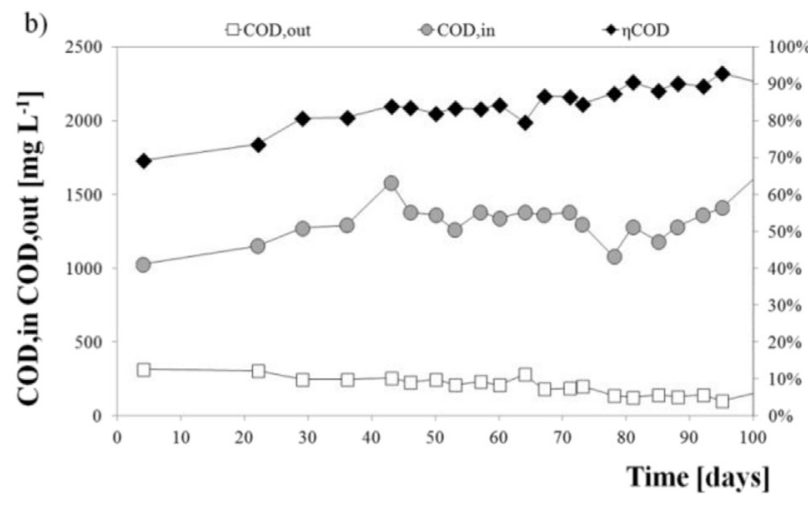

d) $\quad$ NH4-Nin $\quad$ NH4-Nout $\quad$ NO3-Nout $\quad$ NO2-Nout $\quad \Delta \mathrm{TN}$ removal

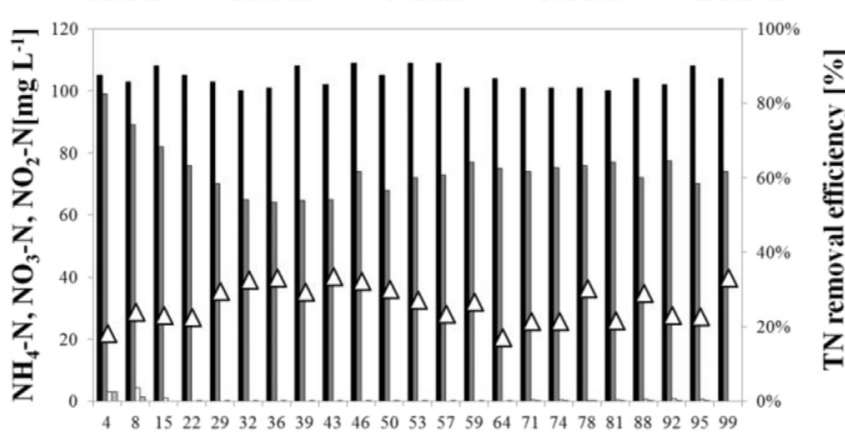

Time [days]

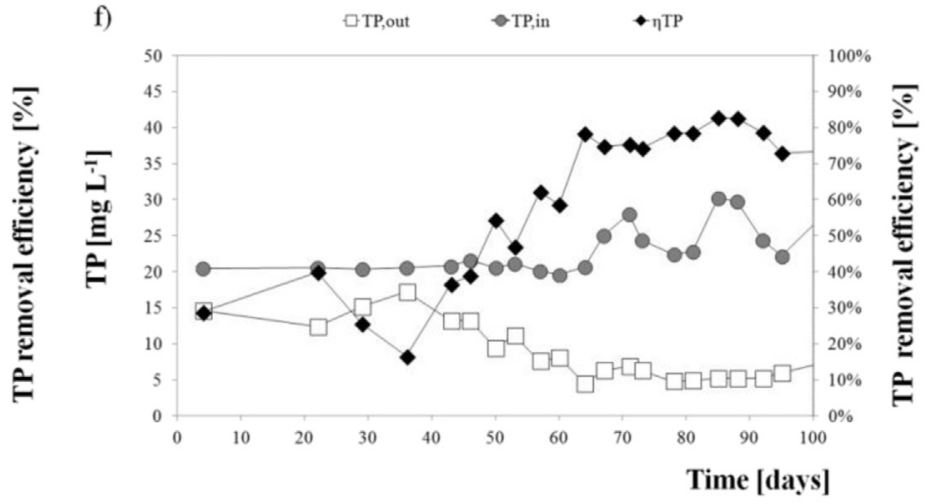

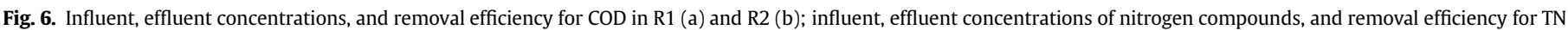
in R1(c); and R2 (d); influent, effluent concentrations, and removal efficiency for TP in R1 (e) and R2 (f).

However, nitrogen and phosphorous removal might provide significant observations regarding granule stratification.

In R1, nitrification efficiency decreased sharply in the first 20 days due to sludge washout, so $\mathrm{NH}_{4}-\mathrm{N}$ concentration in the effluent resulted high (Fig. 6c). In the following weeks, nitrification efficiency slowly increased up to approximately $45 \%$ on the $60^{\text {th }}$ day, when the sludge age stabilized at around 16 days. Ammonium effluent concentration was about $20 \mathrm{mg} \mathrm{l}^{-1}$ and total nitrogen removal was a little more than $50 \%$. After the 66 th day, a significant nitrite accumulation in the effluent was observed (over $20 \mathrm{mg} \mathrm{l}^{-1}$ ), suggesting that the nitrification process was not complete. Denitrification efficiency was very low, due to the small granule dimensions $(1 \mathrm{~mm})$. Effluent nitrate concentration was medium $4 \mathrm{mg} \mathrm{l}^{-1}$. In these conditions in fact, the anoxic layer was quite thin, with respect to the aerobic layer, especially during the famine period when the nitrification process occurs. As a result the simultaneous nitrification/denitrification (SND) process was not complete (Di Bella and Torregrossa, 2013).

In R2, a minimum nitrification activity was observed between the 15th and the 39th day (Fig. 6d). Contrary to R1, no nitrite accumulation occurred. Except for this short period, nitrogen consumption was due to heterotrophic synthesis, so total nitrogen removal was around $26 \%$.

The low efficiency of nitrogen removal observed in $\mathrm{R} 1$ could be attributed to several causes. As confirmed by other studies, in the early stage of granulation process, only carbon removal occurred. Much longer periods, in the order of 60-150 days have been reported for the achievement of high $\mathrm{N}$ removal performances (Lochmatter and Holliger, 2014), due to severe washout occurring in the first weeks of the granulation process. So N-removal process may be a lengthy process because nitrifiers are slow growing microorganisms. In addition, the strong thickening that occurs as a result of cell adhesion in the first stage of the granulation process may significantly reduce the oxygen penetration dept within 
granules, with the consequence that a significant amount of nitrite in the effluent could be observed. As reported by Wang et al. (2007), in aerobic granular sludge ammonium oxidizing bacteria (AOB) develop more rapidly than nitrite oxidizing bacteria (NOB), hence a partial nitrite accumulation in the effluent could be observed during the granulation process.

In R2 nitrification absence cannot be univocally explained. As said before, a minimum nitrification activity between the 15 th and 39th day was observed, when the sludge age was about 16 days. However, as previously said, the SRT resulted lower in R2 for most of the cultivation period. In such conditions, autotrophic microorganism accumulation was difficult to achieve. Therefore, one of the causes could be the failure to achieve steady state conditions in terms of solid retention time. This would confirm the greater time required to remove nitrogen from granular sludge. In addition, it is also true that high salt concentrations rapidly inhibit NOB microorganisms (Bassin et al., 2011), but it is also possible that long term exposure results in the inhibition of $\mathrm{AOB}$ microorganisms. Lastly, as reported by Hu et al. (2005), AOB may be inhibited by synthetic organic compounds, therefore it is possible that hydrocarbons might have inhibited their growth, due to long term exposure. To better understand this aspect future studies are necessary.

During the early stages of the granulation process phosphorous efficiency removal was low for both reactors. After 80 and 40 days respectively, the R1 (Fig. 6e) and R2 (Fig. 6f) granules were sufficiently large, so the anaerobic layer could form, and phosphorous removal was achieved. At the end of the cultivation period, phosphorous removal efficiency was $50 \%$ and $80 \%$ for R1 and R2 respectively. Phosphorous efficiency removal was higher in R2 despite higher influent salinity. As reported by Pronk et al. (2014), high chloride concentrations produce a gradual inhibition of Polyphosphate Accumulating Organisms (PAOs). However, it was also observed that the inhibitory effect is not direct. In fact, the inhibition is due to the presence of high nitrite concentrations, resulting from the partial nitrification process. According to Pijuan et al. (2011), free nitric acids have a greater inhibitory effect on PAOs compared to Glycogen Accumulating Organisms (GAOs), giving a greater competitive advantage to the latter. Similarly, nitrate accumulation, resulting from poor denitrification, might inhibit the PAOs. Hence, if no nitrite or nitrate accumulation occurs, PAOs could acclimate within the granules, therefore phosphorous removal could be achieved. Therefore, in R2 the higher phosphorous efficiency removal observed with respect to $\mathrm{R} 1$, might be due to nitrite or nitrate absence, caused in turn by autotrophic bacteria inactivity. In fact, after the $60^{\text {th }}$ day in R1 a large amount of nitrite and nitrate began to appear in the effluent as a consequence of partial nitrification and denitrification respectively. Bearing in mind what has been said before, efficient nutrient removal has not been the main focus of this work, but its analysis might be used to form hypothesis about granule stratification.

Based on the previous observations and analytical data, it is possible to confirm that the R1 granules had three layers (aerobic, anoxic, anaerobic), while R2 ones had only two (aerobic, anaerobic). The absence of the anoxic layer on the one hand increased the depth of the anaerobic one, and on the other, reduced the competition between the PAOs and GAOs bacteria, improving the efficiency of phosphorous removal.

\subsection{THPs removal}

TPHs analysis was performed in R2 when mature granules were achieved. In Fig. 7a, TPHs concentration and removal efficiency are shown. Until the $30^{\text {th }}$ day, the removal efficiency of TPHs was about $30 \%$, but it increased to close to $50 \%$ on the 55 th day, when the granulation rate reached its maximum value. This is probably attributable to the physical phenomenon of oil droplet adsorption within the granules as previously disclosed. After the 55th day, a considerable increase in the removal efficiency was observed and a value of $90 \%$ on average was reached. As previously observed, after the 55th day, a slight decrease of both the granulation rate and the size of the granules was observed, which implied an increase in the specific area of the granules. This resulted in an increase of the active sites for hydrocarbon adsorption, hence the efficiency of physical removal improved. In addition, from the literature it is known that the EPSs are beneficial for organic pollutant adsorption, since they have hydrophobic properties (Sheng et al., 2010). Thus, as the EPSs content was significantly higher, they possibly played a dominant role in the adsorption process. However, this large increase might be only partially attributed to an improvement in adsorption capacity of aerobic granules. As reported by Moreira et al. (2015) aerobic granules show excellent adsorption capacity. Authors reported that aerobic granules were able to remove about $70 \%$ of fluoxetine influent load by adsorption phenomena. However, under continuous feeding, the adsorption capacity gradually reduced due to saturation of granules adsorption capacity. Similar results were obtained by Amorim et al. (2014) in the treatment of wastewater containing fluoroquinolones (FQs). All these studies show that the removal of pollutants was rapid in the initial stage, but gradually decreased with time until reaching an equilibrium, indicating that the maximum adsorption capacity of granules had been reached. Therefore, if no biological consumption of adsorbed compounds occurred, granules gradually lost their adsorption properties. As a result, if pollutants are mainly removed by adsorption, efficiency removal gradually decreases to zero. However, in this study TPHs removal efficiency did not decrease; indeed, it gradually increased to a steady-state value of about $90 \%$. Therefore, it is possible that TPHs were removed also biologically, although its contribution cannot be exactly quantifiable. As observed by Pendashteh et al. (2012), acclimated microorganisms are able to remove hydrocarbon compounds. In addition, the same authors reported that the increase of hydraulic retention time (HRT) resulted in an improvement in the efficiency of hydrocarbon removal, due to the higher contact time between microorganisms and pollutants. It is well known that granular sludge has high biomass retention due to its dense and compact structure, so a large number of microorganisms develop within these bio-aggregates. Moreover, hydrocarbon adsorption inside the granules imply a longer contact time with microorganisms, promoting their biological degradation. It is worth noting that from the 30th day (Fig. 7b) a gradual increase of the ratio between proteins and carbohydrates, both evaluated at the end of the famine and feast periods, was observed. As reported by Zhu et al. (2012), microorganisms during the feast period degrade readily biodegradable substrate and store energy in the form of polymers to serve as carbon and energy source for endogenous respiration in the aerobic starvation phase (famine period). Therefore, during the famine period, a reduction of EPSs, both in protein and carbohydrate fractions, generally occurs. The increase of the ratio of both proteins and carbohydrates evaluated at the end of the famine $\left(\mathrm{PS}_{\mathrm{f}}\right.$, $\mathrm{PN}_{\mathrm{f}}$ ) and feast periods $\left(\mathrm{PS}_{\mathrm{F}}, \mathrm{PN}_{\mathrm{F}}\right)$, might be likely due to the biodegradation of a slowly degradable substrate (hydrocarbons) during the famine period, that was degraded preferentially instead of the EPSs. On the basis of these considerations, it is reasonable to assert that THPs were removed biologically.

\section{Conclusions}

The granulation process in two GSBAR fed with acetate-based synthetic wastewater and slops was analysed. Aerobic granules successfully developed in both reactors, but the granulation time 
a)

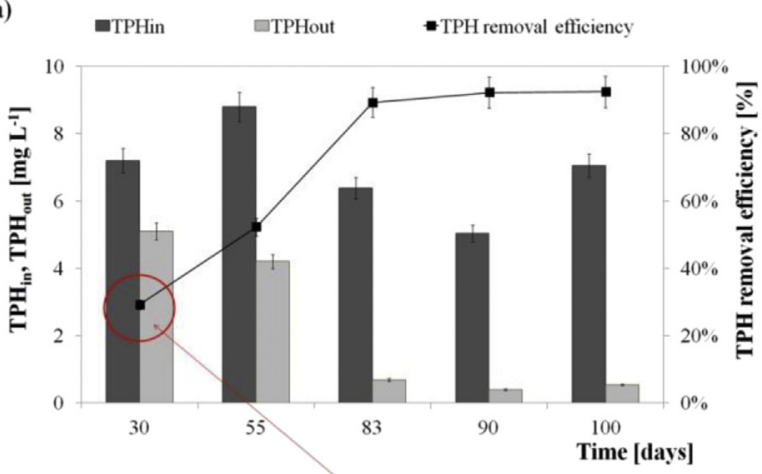

b)

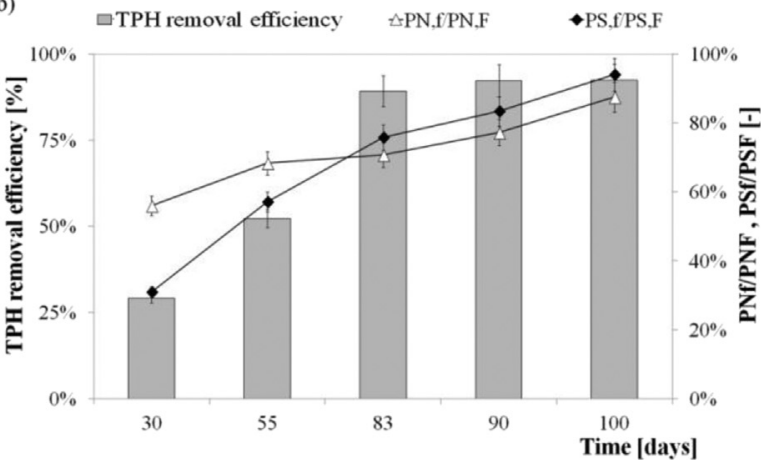

c)

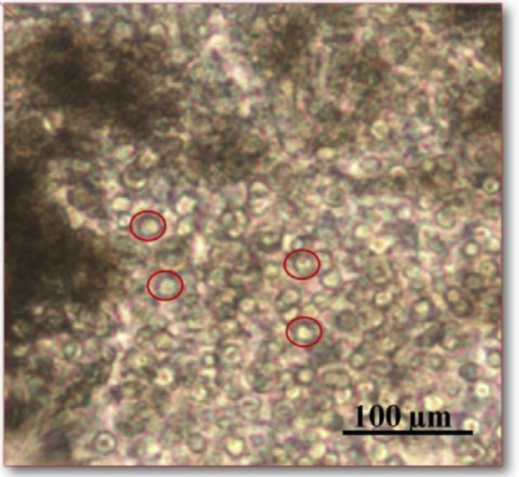

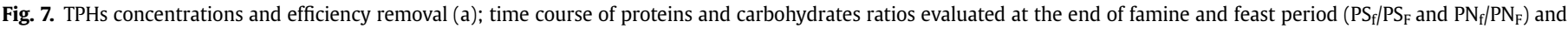
TPHs efficiency removal (b); oil droplet inclusion within the granules (c).

was different. The granules fed with slops developed more quickly than others due to major EPS production and to the trapping of oily particles that increased the sludge hydrophobicity. However they became slightly unstable due to high $\mathrm{Na}^{+}$concentration and also to PN reduction in the long starvation phase. Despite high salinity, excellent performances in terms of carbon removal were obtained. Poor nitrification efficiency was observed in R1 during the first 100 days, confirming that longer times are required for the completion of the process. In R2 a further effect of inhibition due to salinity and to the presence of hydrocarbon compounds on autotrophic microorganisms was hypothesized, and nitrification was practically absent. TPHs were removed both physically and biologically due to longer contact time, with a removal efficiency of over $90 \%$. The results obtained suggest that aerobic granulation could be achieved despite very high salt concentration and hydrocarbon content. Moreover they seem to accelerate the granulation process.

\section{Acknowledgements}

This work was funded by the National Operational Programme for Research and Competitiveness 2007-2013 - Project "STI-TAMPON 02; the Italian Ministry of Education, University and Research and Ministry of Economic Development". Further, the TPH measurements and the characterization of slops were partially funded by the National Operational Programme for Research and Competitiveness 2007-2013. - Project "SIBSAC - An integrated system for sediment remediation and high salinity marine wastewaters treatment".

\section{References}

Abdullah, N., Yuzir, A., Curtis, T.P., Yahya, A., Ujang, Z., 2013. Characterization of aerobic granular sludge treating high strength agro-based wastewater at different volumetric loadings. Bioresour. Technol. 127, 181-187.

Adav, S.S., Lee, D.J., 2008. Extraction of extracellular polymeric substances from aerobic granule with compact interior structure. J. Hazard. Mater. 154 (1-3), 1120-1126.

Amorim, C.L., Maia, A.S., Mesquita, R.B.R., Rangel, A.O.S.S., van Loosdrecht, M.C.M., Tiritan, M.E., Castro, P.M.L., 2014. Performance of aerobic granular sludge in a sequencing batch bioreactor exposed to ofloxacin, norfloxacin and ciprofloxacin. Water Res. 50, 101-113.

APHA, 2005. Standard Methods for the Examination of Water and Wastewater, nineteenth ed. American Public Health Association, Washington DC, USA.

Bartrolí, A., Pérez, J., Carrera, J., 2010. Applying ratio control in a continuous granular reactor to achieve full nitritation under stable operating conditions. Environ. Sci. Technol. 44 (23), 8930-8935.

Bassin, J.P., Pronk, M., Muyzer, G., Kleerebezem, R., Dezotti, M., van Loosdrecht, M.C.M., 2011. Effect of elevated salt concentrations on the aerobic granular sludge process: linking microbial activity with microbial community structure. Appl. Environ. Microbiol. 77 (22), 7942-7953.

Beun, J.J., Van Loosdrecht, M.C.M., Heijnen, J.J., 2002. Aerobic granulation in a sequencing batch airlift reactor. Water Res. 36 (3), 702-712.

De Kreuk, M.K., Pronk, M., Van Loosdrecht, M.C.M., 2005. Formation of aerobic granules and conversion processes in an aerobic granular sludge reactor at moderate and low temperatures. Water Res. 39 (18), 4476-4484.

Di Bella, G., Di Trapani, D., Torregrossa, M., Viviani, G., 2013. Performance of a MBR pilot plant treating high strength wastewater subject to salinity increase: analysis of biomass activity and fouling behaviour. Bioresour. Technol. 147, 614-618.

Di Bella, G., Giustra, M.G., Freni, G., 2014. Optimisation of coagulation/flocculation for pre-treatment of high strength and saline wastewater: performance analysis with different coagulant doses. Chem. Eng. J. 254, 283-292.

Di Bella, G., Torregrossa, M., 2013. Simultaneous nitrogen and organic carbon removal in aerobic granular sludge reactors operated with high dissolved oxygen concentration. Bioresour. Technol. 142, 706-713.

Di Bella, G., Torregrossa, M., 2014. Aerobic granular sludge for leachate treatment. Chem. Eng. Trans. 38, 493-498.

Dubois, M., Gilles, K.A., Hamilton, J.K., Rebers, P.A., Smith, F., 1956. Colorimetric method for determination of sugars and related substances. Anal. Chem. 28 (3), $350-356$.

Hu, Z., Ferraina, R.A., Ericson, J.F., MacKay, A.A., Smets, B.F., 2005. Biomass characteristics in three sequencing batch reactors treating a wastewater containing synthetic organic chemicals. Water Res. 39 (4), 710-720.

Ismail, S.B., de La Parra, C.J., Temmink, H., van Lier, J.B., 2010. Extracellular polymeric substances (EPS) in upflow anaerobic sludge blanket (UASB) reactors operated 
under high salinity conditions. Water Res. 44 (6), 1909-1917.

Jemaat, Z., Suárez-Ojeda, M.E., Pérez, J., Carrera, J., 2013. Simultaneous nitritation and p-nitrophenol removal using aerobic granular biomass in a continuous airlift reactor. Bioresour. Technol. 150, 307-313.

Le-Clech, P., Chen, V., Fane, T.A.G., 2006. Fouling in membrane bioreactors used in wastewater treatment. J. Membr. Sci. 284 (1-2), 17-53.

Li, J., Cai, A., Wang, M., Ding, L., Ni, Y., 2014. Aerobic granulation in a modified oxidation ditch with an adjustable volume intraclarifier. Bioresour. Technol. 157, $351-354$

Liu, H., Li, Y., Yang, C., Pu, W., He, L., Bo, F., 2012. Stable aerobic granules in continuous-flow bioreactor with self-forming dynamic membrane. Bioresour. Technol. 121, 111-118.

Liu, L., Sheng, G.P., Li, W.W., Tong, Z.H., Zeng, R.J., Liu, J.X., Xie, J., Peng, S.C., Yu, H.Q., 2011. Cultivation of aerobic granular sludge with a mixed wastewater rich in toxic organics. Biochem. Eng. J. 57 (1), 7-12.

Liu, Q.S., Liu, Y., Show, K.Y., Tay, J.H., 2009. Toxicity effect of phenol on aerobic granules. Environ. Technol. 30 (1), 69-74.

Lochmatter, S., Holliger, C., 2014. Optimization of operation conditions for the startup of aerobic granular sludge reactors biologically removing carbon, nitrogen, and phosphorous. Water Res. 59, 58-70.

Lowry, O.H., Rosebrough, N.J., Farr, A.L., Randall, R.J., 1951. Protein measurement with the Folin phenol reagent. J. Biol. Chem. 193 (1), 265-275.

Moreira, I.S., Amorim, C.L., Ribeiro, A.R., Mesquita, R.B.R., Rangel, A.O.S.S., van Loosdrecht, M.C.M., Tiritan, M.E., Castro, P.M.L., 2015. Removal of fluoxetine and its effects in the performance of an aerobic granular sludge sequential batch reactor. J. Hazard. Mater. 287, 93-101.

Pendashteh, A.R. Abdullah, L.C., Fakhru'L-Razi, A., Madaeni, S.S., Zainal Abidin, Z Awang Biak, D.R., 2012. Evaluation of membrane bioreactor for hypersaline oily wastewater treatment. Process Saf. Environ. Prot. 90 (1), 45-55.

Pijuan, M., Werner, U., Yuan, Z., 2011. Reducing the startup time of aerobic granular sludge reactors through seeding floccular sludge with crushed aerobic granules. Water Res. 45 (16), 5075-5083.

Pronk, M., Bassin, J.P., De Kreuk, M.K., Kleerebezem, R., Van Loosdrecht, M.C.M., 2014. Evaluating the main and side effects of high salinity on aerobic granular sludge. Appl. Microbiol. Biotechnol. 98 (3), 1339-1348.

Rosenberg, M., Gutnick, D., Rosenberg, E., 1980. Adherence of bacteria to hydrocarbons: a simple method for measuring cell-surface hydrophobicity. FEMS Microbiol. Lett. 9 (1), 29-33.

Sheng, G.P., Yu, H.Q., Li, X.Y., 2010. Extracellular polymeric substances (EPS) of microbial aggregates in biological wastewater treatment systems: a review. Biotechnol. Adv. 28 (6), 882-894.

Sun, C., Leiknes, T., Weitzenböck, J., Thorstensen, B., 2010. Salinity effect on a biofilm-MBR process for shipboard wastewater treatment. Sep. Purif. Technol. 72 (3), 380-387.

Taheri, E., Khiadani Hajian, M.H., Amin, M.M., Nikaeen, M., Hassanzadeh, A., 2012 Treatment of saline wastewater by a sequencing batch reactor with emphasis on aerobic granule formation. Bioresour. Technol. 111, 21-26.

Tay, J.H., Liu, Q.S., Liu, Y., 2001. Microscopic observation of aerobic granulation in sequential aerobic sludge blanket reactor. J. Appl. Microbiol. 91 (1), 168-175.

Val del Río, A., Figueroa, M. Arrojo, B., Mosquera-Corral, A., Campos, J.L., GarcíaTorriello, G., Méndez, R., 2012. Aerobic granular SBR systems applied to the treatment of industrial effluents. J. Environ. Manag. 95 (Suppl.), S88-S92.

Verawaty, M., Tait, S., Pijuan, M., Yuan, Z., Bond, P.L., 2013. Breakage and growth towards a stable aerobic granule size during the treatment of wastewater: Water Res. 47 (14), 5338-5349.

Wan, C., Yang, X., Lee, D.J., Liu, X., Sun, S., Chen, C., 2014. Partial nitrification of wastewaters with high $\mathrm{NaCl}$ concentrations by aerobic granules in continuousflow reactor. Bioresour. Technol. 152, 1-6.

Wang, F., Xia, S.q., Liu, Y., Chen, X.s., Zhang, J., 2007. Community analysis of ammonia and nitrite oxidizers in start-up of aerobic granular sludge reactor: J. Environ. Sci. 19 (8), 996-1002.

Zhang, H., He, Y., Jiang, T., Yang, F., 2011. Research on characteristics of aerobic granules treating petrochemical wastewater by acclimation and co-metabolism methods. Desalination 279 (1-3), 69-74.

Zhu, L., Qi, H.Y., Lv, M.L., Kong, Y., Yu, Y.W., Xu, X.Y., 2012. Component analysis of extracellular polymeric substances (EPS) during aerobic sludge granulation using FTIR and 3D-EEM technologies. Bioresour. Technol. 124, 455-459. 